\title{
Política vasca de garantía de ingresos: los riesgos de criminalización de la pobreza de un modelo condicional
}

\section{Isabel Torre Millán}

Hegoa-Instituto de Estudios sobre Desarrollo y Cooperación Internacional (UPV/EHU) <itorre015@ikasle.ehu.es>

\begin{abstract}
Azken urteetan, gizarte babeserako politiketan europar joerek orientazio argia izan dute aktibaziorantz. Aktibazioaren paradigmak, euskal politikak diru-sarreren bermearekin onartzen duena, maila batean pobreziaren kriminalizazioa erakusten duela aldezten du artikulu honek, eta halaber, horrek dakarren arriskuaz ohartarazten. Horretarako diskurtsoaren analisi bat aurkezten da, eta kritikoki aztertzen ditu Euskadin aktibazioaren paradigma sostengatzen dituzten oinarriak. Artikuluak bere ikerketaren baitan biltzen ditu ideologia neoliberalak eta sistema kapitalistak izan dezaketen eragina.
\end{abstract}

\section{GAKO-HITZAK:}

Gizarteratzeko gutxiengo errentak, Euskal Autonomia Erkidegoa, diskurtsoaren azterketa, pobrezia, neoliberalismoa, hirugarren bidea.
En los últimos años, las tendencias europeas en las políticas de protección social están acusando una clara orientación hacia la activación o la condicionalidad laboral. Este artículo defiende que el paradigma de la activación, asumido por la política vasca de garantía de ingresos, presenta un cierto grado de criminalización de la pobreza, y alerta del peligro que esto conlleva. Para ello, se presenta un análisis de discurso que examina, de forma crítica, los principios que sustentan el paradigma de la activación en Euskadi. El artículo integra en su estudio la posible influencia de la ideología neoliberal y del propio sistema capitalista.

\section{PALABRAS ClaVe:}

Rentas mínimas de inserción, País Vasco, análisis del discurso, pobreza, neoliberalismo, tercera vía. 


\section{Introducción}

En el actual periodo de ofensiva neoliberal, las políticas de protección social, que dedican su esfuerzo al tratamiento de las personas sin recursos, esconden, de manera subrepticia, la perspectiva de criminalización de la pobreza, que aquí se quiere desentrañar. Es por ello por lo que se ha dedicado este artículo a analizar el modelo de protección social contra la pobreza implantado actualmente en el País Vasco, centrando la atención en la activación laboral.

En un intento por definir el término ‘activación', Barbier establece que "hay activación cuando se introduce una vinculación explícita (a menudo reglamentaria) entre la protección social y las políticas de empleo y del mercado de trabajo" (cit. en Pérez Eransus, 2005: 122). Originariamente, la activación no contemplaba la participación de aquellos colectivos que estaban muy alejados del mercado laboral, como ocurrió en la Suecia de los años cincuenta. En los años ochenta, y en medio de una crisis de empleo, los países europeos pensaron que las políticas de activación supondrían una buena medida para asimilar los niveles de cualificación de las personas desempleadas a las necesidades del mercado laboral. Sin embargo, es en los años noventa, cuando el desempleo desciende y, por tanto, hay mayor disponibilidad de puestos de trabajo, cuando se empieza a consolidar la exigencia de condicionamientos laborales al cobro de las prestaciones asistenciales (Pérez Eransus, 2005: 309). Algunos autores consideran que este hecho supone un retroceso en el tratamiento de la pobreza respecto al logro constituido por los sistemas de protección en el siglo XX (Pérez Eransus, 2005: 171). Según Torfing (1999, cit. en Inza, 2012: 122), la aceptación del paradigma de la activación, que sustituye a las provisiones pasivas tradicionales, supone un paso desde los derechos incondicionales (o con casi ninguna reserva) a la condicionalidad de unos llamados derechos sociales respecto al cumplimiento de ciertas obligaciones de orientación laboral. Pérez Eransus puntualiza: mientras que en los países socialdemócratas el paradigma de la activación se concibe en su vertiente rehabilitadora o integradora, el fin perseguido con la activación en un país como EE.UU. es, más bien, el de disuadir a los pobres de la vida en la asistencia, lo que se enmarca en una doble estrategia que pretende reducir el gasto social y promover la aceptación de trabajos precarios (2005: 124, 311).

Respecto a la expresión 'criminalización de la pobreza', se refiere aquí a una idea cercana al concepto de culpabilización, esto es, asignar responsabilidades individuales o culpar a las personas pobres de su propia situación de pobreza. Y es que responsabilizar del crimen de la pobreza es, a fin de cuentas, criminalizar.

De cara a atestiguar esta perspectiva culpabilizadora en las políticas vascas de protección social, se ha realizado un análisis crítico de aquel discurso que defiende e inspira el desarrollo del paradigma de la activación en la política de garantía de ingresos de la Comunidad Autónoma del País Vasco (CAPV).
Antes de comenzar la exposición de cuestiones que sustentan la idea de que el modelo vasco de garantía de ingresos esconde una lógica de criminalización de la pobreza, lógica que rechazamos y tratamos de combatir, no podemos dejar de reconocer el esfuerzo en la promoción de iniciativas de activación por parte de personas bienintencionadas, y celebramos aquellos casos que hayan supuesto una mejora sustancial en el bienestar de las personas usuarias de los programas, máxime cuando se haya conseguido su verdadera inclusión social.

La estructura del artículo es la siguiente:

- El primer apartado se ha reservado para presentar el corpus analizado, incluyendo la motivación principal para su selección, así como una breve descripción de su contenido.

- En el segundo apartado, se analizan las principales ideas del texto seleccionado, examinando bajo qué modelo interpretativo pueden haber sido formuladas.

- En el siguiente apartado, se recogen las ideasfuerza del discurso analizado y se estudia la triple conexión entre el neoliberalismo, el paradigma de la activación de la política vasca de garantía de ingresos y la criminalización de la pobreza.

- El apartado de conclusiones resume las principales ideas extraídas a lo largo del trabajo y expone algunas consideraciones al respecto.

\section{Presentación del corpus analizado}

El documento analizado surge a raíz del proceso de cambio del antiguo Sistema Vasco de Garantía de Ingresos, cuya responsabilidad en la gestión de los dispositivos de garantía de ingresos fue trasladada desde los departamentos municipales y forales de servicios sociales al, por aquel entonces, recién formado Servicio Vasco de Empleo Lanbide. Concretamente, el documento es un informe elaborado por el SIIS Centro de Documentación y Estudios, de la Fundación Eguía-Careaga, y publicado en septiembre de 2011 bajo el nombre de Activación y derecho a la inclusión en el marco de las políticas de empleo y de garantía de ingresos en la CAPV.

Como es bien sabido, y tal y como establece la Ley 12/1998, de 22 de mayo, contra la Exclusión Social, el empleo como contrapartida para el acceso a las prestaciones sociales ha acompañado siempre al sistema vasco de garantía de ingresos, en mayor o menor medida. Sin embargo, el propio informe arriba referenciado reconoce que la transformación organizativa llevada a cabo en 2011 trajo también consigo una cierta transformación conceptual, que enfatizaba la importancia de la centralidad del empleo como herramienta para la inclusión social, coincidiendo con el cambio de orientación de las políticas sociales que ya venía dándose en otros países europeos (SIIS, 2011). Es por ello por lo que se ha creído oportuno utilizar este informe como texto base sobre el que escrutar 
las motivaciones que promueven el paradigma de la activación en la política vasca de garantía de ingresos.

El objetivo del informe, manifestado como tal por las personas autoras, es el de "proponer una serie de líneas de reflexión, de carácter teórico, sobre la aplicación del concepto de activación a la gestión de las políticas de garantías de ingresos y de empleo, que sirva de marco conceptual y filosófico al modelo de intervención de Lanbide" (ibídem: 5). Del entrecomillado extraído se desprende que el texto se dirige a los y las trabajadoras del Servicio Público de Empleo Lanbide. No obstante, se puede adivinar un desarrollo orientado a convencer a posibles receptores secundarios.

El informe se divide en tres secciones. La primera se ofrece a modo de introducción, justificando la motivación del documento, así como explicando algunos elementos conceptuales básicos. La segunda sección describe someramente las políticas de activación introducidas en los países del entorno desde la década de los ochenta, especificando sus características básicas de acuerdo a los modelos identificados en la literatura. En cuanto a la consideración que el concepto de activación ha tenido históricamente en el Sistema Vasco de Garantía de Ingresos, el informe evalúa hasta qué punto se puede hablar de una ruptura con el enfoque tradicional. Por último, este bloque incluye el resumen de algunas críticas al paradigma de la activación encontradas en la literatura. La tercera y última sección establece los elementos conceptuales básicos que, según defiende, deberían sustentar las políticas de activación en la CAPV; define, después, lo que considera las características básicas de un modelo inclusivo de activación y, por último, propone algunas herramientas que habría que tener en cuenta.

Debido a que lo que aquí se pretende estudiar es la postura política que defiende el énfasis en la activación laboral en el ámbito de la garantía de ingresos y la inclusión para descubrir si esconde un enfoque de criminalización de la pobreza, se ha decidido centrar el análisis del discurso en un apartado de la tercera sección del informe, el cual determina el marco conceptual y filosófico del nuevo modelo. Nos referimos al apartado 3.1 del documento, titulado "Elementos conceptuales básicos para la definición de un nuevo modelo: la inclusión activa como derecho y como deber de las personas sin ingresos en situación de desempleo". Tanto el capítulo concreto analizado como el resto del informe escogen sus argumentos desde el prisma de la filosofía moral y política, dejando a un lado cuestiones como la efectividad o la adecuación técnica del modelo defendido. La misma aproximación para el análisis es, pues, seguida por nosotros.

\section{El discurso del informe del SIIS sobre la activación}

En primer lugar, llama la atención que, en las líneas introductorias del documento del SIIS, las personas autoras dejen fuera del debate la cuestión misma de la pertinencia del paradigma de la activación, centrando el informe en la elección de los componentes básicos de un modelo concreto de activación que se configure mediante concepciones teóricas éticamente justificables. Lo que apuntan como justificación no es un argumento ético ni filosófico, sino el hecho de que "los países europeos han llevado a cabo plasmaciones diversas del nuevo paradigma activador" (ibídem: 72), pasando a continuación a centrar el debate en el "ambivalente entendimiento del nuevo paradigma de la activación -que oscila entre la potenciación de los principios regulativos y de solidaridad, y la introducción de una mayor individualización y remercantilización del bienestar humano-" (ídem). Con la sola justificación de que los países europeos acogen el nuevo paradigma y poniendo, en su lugar, la configuración del modelo ideal como centro del debate, el SIIS acota el ámbito de discusión a aquel que no cuestiona el principio de condicionalidad de la protección social basada en el empleo.

Por si quedase alguna duda de la conveniencia de partir de dicha base incuestionable, en el texto se asimilan los modelos de activación con los modelos de inclusión activa, lo que, dado el valor que representa la noción de inclusión, contribuye a la construcción positiva de la percepción simbólica del término ‘activación'. Es destacable, además, la buena estimación que, por sí misma, adquiere la palabra 'activa/o' y todas aquellas de su misma raíz.

Unido directamente a lo anterior, es importante remarcar que, a excepción de un fragmento, situado casi al final del texto analizado, no se hace mención especial a la propia inclusión social. Es llamativo que a lo largo de las diez páginas se defiendan ideas como la centralidad del empleo, la reciprocidad, la legitimación ciudadana, la reducción del gasto público o el apoyo de los expertos, pero que hasta la antepenúltima página no desarrolle, en forma de apartado, lo que han llamado "principio de inclusión social" (ibídem: 79).

\subsection{Extensión del propio paradigma}

Después de haber dado por ineludible la aceptación del paradigma de la activación, el texto alude a las voces críticas para comenzar a justificar las razones concretas de su defensa. Siguiendo con el argumento de las líneas introductorias y aceptando, esta vez, que no constituye el argumento determinante, el SIIS apunta a "la extensión cuasi universal del paradigma y a su aceptación en todos los países de nuestro entorno, incluso en los que vienen desarrollando políticas sociales más progresistas" (ibídem: 73). Este argumento no es central, como el propio documento reconoce, pero tampoco constituye un argumento filosófico o moral; sin embargo, es esgrimido por su utilidad práctica a la hora de obtener mayor aceptación social. 


\subsection{Importancia del empleo remunerado}

El documento analizado comienza su lista de argumentos determinantes apelando a la importancia del empleo remunerado como "mecanismo esencial de inclusión social, de realización personal y de protección contra la pobreza" (ibídem: 73). Cabe destacar que tal afirmación se sostiene incluso con el reconocimiento de las "actuales circunstancias de precarización del mercado de trabajo" (ibídem: 73). Mantienen la misma concepción superlativa del empleo defensores del Estado social inversor como Jenson y Saint-Martin, quienes opinan que "el trabajo es la ruta para la maximización del bienestar del individuo y que el bienestar de la sociedad y la cohesión social depende de esa actividad” (Inza, 2012: 125).

El documento del SIIS cita a Pérez Eransus, la cual destaca "la potencialidad del empleo como factor de integración social [...] [en] la lucha contra la exclusión" (SIIS, 2011: 73) y admite que "frecuentemente ayuda a mejorar las condiciones de vida en términos económicos, de acceso a la protección social y en la promoción de procesos de integración social” (ibídem: 73-74). Basándose en estos datos, el texto analizado defiende que toda política de inclusión social debe tener como objetivo primordial ofrecer a las personas desempleadas, o con empleos poco remunerados, las herramientas necesarias para la mejora de su empleabilidad. Así, el documento asume una concepción simplificada de la realidad social en la que se da por válido el esquema de mercantilización de la vida, donde sólo el trabajo remunerado puede proporcionar a la ciudadanía recursos económicos y derecho a la protección social. De la misma manera, se simplifica el enfoque de la mejora de la empleabilidad de las personas, el cual traslada la responsabilidad al plano individual. Esta concepción reduccionista del término 'empleabilidad' alienta un escenario en el que empleos poco remunerados son intercambiados entre distintas personas trabajadoras según algunas de ellas ascienden en el sistema de estratificación social, mientras que la existencia de tales puestos de trabajo precarios sigue estando garantizada en el mercado laboral, que continúa demandando mano de obra barata. La perspectiva que aboga por la "mejora de la empleabilidad de las personas" o "el desarrollo del capital humano" (ibídem: 79) es propia de los adeptos de la "tercera vía', que proponen el citado capital humano "como mejor respuesta a la desindustrialización, demanda de servicios y la emergencia de la economía del conocimiento" (Inza, 2012: 125).

Si bien, más adelante, el documento dice entender la empleabilidad en una perspectiva amplia (SIIS, 2011: 75), este apartado dedicado al empleo le quita el sentido amplio que se le habría atribuido y limita la concepción del término a aquella pensada como característica de las personas, la adecuación de las habilidades individuales a las necesidades del mercado de trabajo, sin atender a ni incidir en la situación concreta del propio mercado de trabajo. De hecho, el olvido respecto a la grave situación de éste se manifiesta una vez más en el texto analizado cuando se reconoce la existencia de personas con empleo y, por tanto, integradas en el mercado laboral, pero que no cuentan con recursos económicos suficientes, y se propone como solución una transferencia de renta que complemente esos ingresos escasos, de manera que puedan cubrir sus necesidades básicas (ibídem: 79). Este tipo de propuestas se enmarcan en las políticas sociales del Estado inversor, las cuales operan como un factor productivo, de cara a lograr una mayor competitividad del mercado de trabajo (Inza, 2012: 123).

Por otra parte, al final del documento analizado se reconoce que, si bien el empleo remunerado tiene una función sobresaliente de inclusión social, ésta "puede alcanzarse desde muy diversos ámbitos vitales, y no sólo desde la inclusión laboral” (SIIS, 2011: 79-80). El texto resulta un tanto confuso, ya que, a continuación se insiste en que "el acceso al empleo ordinario resulta [...] un requisito fundamental, para las personas en edad laboral, para el acceso a una situación de inclusión social plena" (ibídem: 80). Por un lado, se reconoce la multicausalidad de la inclusión, pero, por otro, parece que este reconocimiento es tal sólo a medias, al establecer que sólo en "algunos casos la inserción laboral ha de supeditarse a la consecución de otros objetivos prioritarios en términos de salud, relaciones personales o funcionamiento social” (ídem). A partir de este reconocimiento ambiguo de la multicausalidad de la inclusión, el texto parece abrir la puerta al planteamiento de procesos de inserción ligados a las actividades socialmente útiles, y no sólo al empleo remunerado. Esta idea resulta interesante y, en cierta forma, rompedora. Sin embargo, no se hace mayor alusión a este asunto a lo largo del documento analizado. Si buscamos qué se dice al respecto en el resto del informe, podemos comprobar que el empleo remunerado sigue siendo considerado como el objetivo fundamental, mientras que sólo para algunas personas podría resultar “más eficaz y más justo [...] [que su contribución] se traduzca en la participación en programas de formación, de rehabilitación psicosocial y/o de adquisición de unas capacidades relacionales y laborales básicas” (ibídem: 119).

\subsection{Necesidad de la reciprocidad}

El argumento de la reciprocidad es el que adquiere mayor relevancia si atendemos al espacio reservado para su defensa. Citando a White, el SIIS señala que "el derecho a la garantía de ingresos se basa en una interpretación en clave ética de la autonomía individual, en virtud de la cual las personas no deben, si pueden evitarlo, constituirse en una carga para sus conciudadanos, lo que supondría una forma de explotación" (ibídem: 74). El hecho de llegar a hablar de "explotación" parece querer enfatizar el mensaje; sin duda, resulta paradójico que se hable en esos términos sobre el sector de la población, los perceptores de las rentas de garantía de ingresos, que más probabilidad tiene de acabar siendo explo- 
tado. El informe sigue así: "por las mismas razones, no deben rehuir, si pueden realizarlo, el esfuerzo que otros realizan para el sostenimiento de la comunidad y deben contribuir razonablemente, en la medida de sus posibilidades, a la construcción del bien común" (ídem). En un tono similar, el documento pasa a citar textualmente a Marshall: "si se invoca la ciudadanía para la defensa de los derechos, los correspondientes deberes de ciudadanía no pueden ser ignorados" (ídem). Tales mensajes emanan de la lógica de los derechos y las responsabilidades que, al igual que hemos visto anteriormente con otras cuestiones, coincide con los principios de la tercera vía de Giddens. Éste, al contrario de lo que hacía la antigua socialdemocracia europea, ya no considera los derechos como exigencias incondicionales. En su Estado social inversor, la preminencia de los derechos es socavada por una concepción de la vida en sociedad que podría resumirse con el lema propuesto por el propio Giddens: "Ningún derecho sin responsabilidad” (Inza, 2006: 127).

El tono del discurso se torna más áspero cuando de lo que se trata es de defenderse de las críticas sobre el presunto carácter re-mercantilizador del paradigma de la activación. En ese momento, se viene a recordar que las "prestaciones de garantía de ingresos se conceden a las personas que acreditan tener necesidad de ellas", para, a continuación, apuntar que "parece obvio que la opción individual por la inactividad no se corresponde estrictamente con una situación de necesidad" (SIIS, 2011: 74). El párrafo concluye con la opinión, escrita en negrita, de que "las personas en situación de necesidad económica debido a su inactividad laboral deben poner los medios razonablemente necesarios para salir, si es posible, de esa situación" (ibídem: 75). Observamos así cómo en la sección dedicada a defender la concepción de reciprocidad, el lenguaje utilizado resulta más duro, al remitir a los deberes individuales y no mencionar uno de los conceptos más aludidos en el resto del documento: el de la inclusión social.

En un intento de resumir los derechos sociales y obligaciones individuales que conforman la reciprocidad justa que defienden, llaman la atención varios aspectos. Por un lado, al mencionar el doble derecho, en el que a lo largo del resto del informe se incluye el derecho a recibir apoyos para la inserción social y laboral, así como el derecho a la percepción de una renta mínima adecuada, no se hace, en este apartado, alusión directa a este segundo aspecto más que para resaltar la importancia del primero: "Se trata, pues, del ejercicio de un derecho individual -distinto del derecho a la prestación económica-y del consiguiente compromiso institucional, en el sentido de ofrecer esos apoyos para la empleabilidad, entendida esta última en una perspectiva amplia" (ídem). A continuación, el texto insiste en la idea de que el doble derecho no se limita a la provisión de una prestación económica, y se atreve a afirmar que ésta "en ningún caso garantiza por sí sola la inclusión social” (ídem). Vemos cómo una de las pocas ocasiones en las que se menta la inclusión social en el texto analizado es para asegurar que la prestación económica no la garantiza. Tanto esto último como el hecho de no proclamar la renta mínima como derecho consiguen despojar de valor a la propia prestación económica, al tiempo que acaba situando el debate en torno a las obligaciones o los derechos que sirven al cumplimiento de tales obligaciones (apoyos para la empleabilidad).

Al hilo de la mención de estos derechos concebidos para el cumplimiento de las obligaciones, merece la pena reflexionar sobre la noción de doble derecho antes de pasar al siguiente punto. La idea del doble derecho resulta tramposa, por cuanto los derechos pueden ser ejercidos o no, pero si las acciones a las que se refieren son coercitivas, dejan de ser derechos y se convierten en obligaciones. Llamar derecho a la obligación de mejorar la llamada empleabilidad de la persona, bien sea con la realización de un cursillo, bien con la celebración de entrevistas o el uso de otro tipo de herramientas, es querer disfrazar la realidad. A menos que la aceptación de tales mecanismos de adaptación de las habilidades personales a las necesidades del mercado laboral sea voluntaria, no puede hablarse de derecho como tal.

Pasando a la cuestión de las obligaciones individuales contraídas, el párrafo coincide con la idea planteada en otras secciones del informe, al considerar legítimo requerir a la persona desempleada "una contribución productiva para el adecuado funcionamiento de la sociedad" (ídem). De hecho, el texto aclara: "no es un pago por los servicios recibidos, ni la devolución de una deuda, sino una contribución al funcionamiento de la sociedad" (ibídem: 76). Parecería que la conjunción de ambas sentencias estuviera escondiendo otra verdad. Y es que la exigencia de una contribución productiva no puede entenderse si no es como contraprestación o pago de los servicios prestados, ya que si se quiere pensar en contribuciones al funcionamiento de la sociedad, se deberían admitir las muy diferentes formas de aportación al bien común, no necesariamente ligadas al mercado laboral.

Por otra parte, a aquello que la sociedad está legitimada a pedir a las personas perceptoras de prestaciones, el documento añade: “un esfuerzo personal para salir de la situación de necesidad en la que se encuentran" (ibídem: 75). En esta exigencia se vislumbra no tanto la necesidad de una contribución al bien común en pro de la aludida reciprocidad, sino más bien cierto matiz moralista, así como la asunción de responsabilidades individuales en las situaciones de exclusión.

Llama la atención que se hable sobre la exclusión cuando se trata de defender la exigencia de que las personas perceptoras contribuyan al funcionamiento de la sociedad, esto es, a la hora de establecer obligaciones individuales, y se afirme, citando a Gorz, que "la exención de este deber de contribución es, por el contrario, fuente de exclusión” (ibídem: 76). Por otro lado, más adelante, sí se contempla la 
posibilidad de que estas personas puedan "renunciar al derecho a la recepción de unos apoyos determinados" (ídem), sin alertar en este caso de lo que ello podría significar en términos de exclusión.

Por último, es únicamente para defender el paradigma de la activación para lo que el documento alude directamente a las propias personas afectadas. La única vez que se las trata como agentes con voz propia es cuando se muestran a favor de lo que el informe defiende: "La justificación del modelo de inclusión activa en términos de ampliación de derechos sociales se justifica también desde el punto de vista de las preferencias de las propias personas afectadas, que demandan preferentemente, frente al derecho a una prestación económica incondicional, apoyos para acceder a un empleo" (ídem). Además, no parece que se le dé especial valor a esta opinión, puesto que no se muestra referenciada para posibilitar su comprobación o profundizar en ella.

Hemos visto cómo, en términos generales, el apartado dedicado a la reciprocidad pone el acento en las responsabilidades individuales, y deja de lado tanto los derechos como la propia inclusión social. A pesar de ello, el lenguaje que utiliza incluye el concepto de reciprocidad justa. Esta noción es también apuntada al final del documento analizado, para aludir a la responsabilidad no sólo de "la Administración [...] [sino] también de las empresas y de la sociedad civil, [...] [de] garantizar un mercado de trabajo inclusivo, unas relaciones laborales justas [...] y unos servicios de apoyo individualizados y de calidad" (ibídem: 80). Puesto que todas estas condiciones no están incluidas contractualmente en los llamados convenios de inclusión, no puede decirse que las buenas intenciones puedan esperar corresponderse con la realidad, sobre todo, teniendo en cuenta la precariedad existente en el mercado. De hecho, parece poco probable que las empresas se impliquen en establecer relaciones laborales justas en un contexto de máxima competitividad y continua desrregulación. Todo parece indicar que la pretendida igualdad de oportunidades que promete la llamada reciprocidad justa está destinada a quedar en papel mojado.

En cualquier caso, más allá de la duda que plantea la posibilidad de dicha reciprocidad justa, es oportuno destacar que el discurso analizado no alude a la igualdad, pero sí pone en valor "garantizar la igualdad de oportunidades” (ibídem: 81). De nuevo, este discurso coincide con los posicionamientos de la tercera vía, que ve con buenos ojos las reformas que permitan condicionar legítimamente las provisiones de bienestar al comportamiento individual, acotando la actuación del Estado a una redistribución de posibilidades:

[...] la redistribución no debe desaparecer del programa de la socialdemocracia. Pero el debate reciente entre socialdemócratas ha dirigido el énfasis, bastante razonablemente, hacia la 'redistribución de posibilidades'. El cultivo del potencial humano debería reemplazar en cuanto fuera posible a la redistribución 'tras los hechos' (Giddens, 1999: 121).

\subsection{Reducción del gasto pasivo}

El texto referenciado destaca como objetivo fundamental la optimización del gasto público. A pesar de que no resulta sencillo enmarcar este argumento como filosófico o moral, el SIIS lo suma al debate:

El paso de la percepción de prestaciones económicas financiadas por los presupuestos públicos a la percepción de un salario financiado por una empresa pública o privada, además de generar retornos para la Administración en forma de cotizaciones e impuestos sobre la renta, tiene la virtud fundamental de liberar los recursos económicos públicos que previamente se destinaban a la prestación (SIIS, 2011: 76).

Podemos observar el valor negativo que se le da a las prestaciones económicas en tanto en cuanto destinar menos recursos económicos a éstas recibe el nombre de "liberar" los recursos económicos. Si se pueden liberar, es que su destino actual significa una carga. El modelo interpretativo que sustenta esta visión es aquel que valora todo intercambio monetario que se produzca dentro del mercado laboral y, sin embargo rechaza lo que se ha dado en llamar gasto pasivo, es decir, proveer de recursos económicos a las personas al margen del mercado laboral; recursos que, por otra parte, serían inmediatamente volcados al circuito económico de mercado. El rechazo al gasto pasivo cuadra con la teoría del progreso, propia del discurso neoliberal.

El SIIS continúa su argumentación: “Ciertamente, esa liberación de recursos podría posteriormente utilizarse para reducir el nivel de gasto público [...] o, por el contrario, ser destinada a otros ámbitos de las políticas sociales" (ibídem: 76-77). Este respaldo a reservar recursos públicos a otras políticas sociales se puede entender como una defensa del llamado gasto activo, que también caracteriza al discurso giddensiano, y que incluye las transferencias destinadas a implantar "incentivos de trabajo, beneficios impositivos y otras medidas diseñadas para ofrecer apoyo público a la responsabilidad privada" (Inza, 2014: 58).

\subsection{La legitimación ciudadana}

El texto analizado pone sobre la mesa la legitimación ciudadana, y para ello, se sirve de la opinión de Bennet y Cooke, quienes remarcan la importancia de unos altos niveles de apoyo popular para garantizar la viabilidad del Estado de bienestar. Según ellos, el nivel de apoyo se basará en la percepción social de las políticas sociales, que valore que éstas sean justas y equilibradas. El SIIS parece coincidir en que "un sistema que reclama de los beneficiarios de las ayudas sociales una contribución por la ayuda reci- 
bida atraería a todas aquellas personas que valoran la reciprocidad y el mérito, y podría incrementar los niveles de apoyo social a este tipo de medidas" (2011: 77).

Se hace referencia a la necesaria legitimación ciudadana para mantener un Estado de bienestar que, por otra parte, ya se encuentra en constante desintegración, y no por falta de legitimación popular, precisamente. En referencia a esta última, lo que el documento obvia es el poder de las instituciones sociales a la hora de forjar la percepción de la sociedad de las políticas de protección social. El texto alude a las personas que valoran el mérito, algo bastante común en las sociedades capitalistas actuales. Desde una perspectiva crítica del conflicto, no podría ignorarse que el desarrollo histórico de las actuales instituciones sociales moldea los comportamientos y las relaciones sociales, forja su propia hegemonía cultural. Desde esta perspectiva, se podría intuir que se está utilizando el consentimiento construido desde el poder para realimentar estas mismas relaciones de poder.

Por el contrario, el modelo interpretativo subyacente en el discurso analizado es el funcionalista sistémico, el cual cree en la necesidad de un proceso continuo de legitimación que mantenga el consenso en torno a las normas y principales valores de la sociedad, de manera que se garantice su buen funcionamiento. Estas normas y valores justifican las desigualdades existentes, las cuales son reivindicadas como necesarias para la salud y la supervivencia de la sociedad. Esta concepción impide que los que reciben menos recompensas supongan una amenaza al sistema (Kerbo, 2004: 84). Así, cuando el texto reproduce, sin más, los resultados de las encuestas que dicen que el $88 \%$ de la población vasca piensa que se deberían eliminar las ayudas sociales a quienes rechacen un trabajo o falten a los cursos de formación (SIIS, 2011: 77), se sitúa dentro del paradigma no crítico del orden, es decir, no critica el statu quo y, a su vez, subraya el orden como modelo de sociedad. A la hora de elaborar un discurso en un ámbito tan sensible como el de la pobreza, resulta fundamental un enfoque más pedagógico, que observe de manera crítica los resultados de las encuestas y ofrezca una profunda reflexión sobre este tipo de propuestas.

\subsection{El apoyo de los profesionales}

Como último argumento en defensa del paradigma de activación en el marco de las políticas públicas de protección social, el texto analizado destaca su apoyo por parte de la mayoría de los profesionales del ámbito de los servicios sociales que participaron, en 2010, en un panel de expertos. Una de las principales razones argumentadas por los propios expertos, y subrayada así en el texto, venía dada por el "impulso a la activación de los perceptores de las prestaciones de garantía de ingresos” (ibídem: 78). Se pone aquí el acento en las teorías de la elección racional, las cuales, en este contexto, tienden a aso- ciar la percepción de ayudas a la pasividad y holgazanería. A este respecto, cabe añadir que fueron las dudas sobre el fraude lo que dio lugar al traspaso de la gestión de la renta de garantía de ingresos (RGI) al Servicio Vasco de Empleo Lanbide. Observamos, de nuevo, que el discurso analizado se circunscribe en el paradigma no crítico del orden, cuya lógica sugiere una desconfianza en la naturaleza humana.

\section{La triple conexión: neoliberalismo-activación-criminalización}

Tras haber realizado el análisis del discurso que inspira la política de garantía de ingresos de la CAPV, este apartado recoge nuestra reflexión respecto a las posibles conexiones entre el paradigma de la activación presente en dicha política, el neoliberalismo y la criminalización de la pobreza.

En el informe del SIIS Centro de Documentación y Estudios, no se aprecia el reconocimiento de ruptura alguna en las últimas medidas tendentes a asegurar la activación laboral de las personas perceptoras de prestaciones de garantía de ingresos, respecto al modelo preexistente en la Comunidad Autónoma Vasca. Si bien es verdad que la lógica de condicionamientos laborales ha venido articulando los servicios de garantía de ingresos de la CAPV desde sus orígenes, el traspaso de las políticas de inclusión al nuevo dispositivo de empleo, Lanbide, muestra una creciente orientación activadora en las políticas sociales. Por otra parte, con objeto de contextualizar el inicio del programa vasco de rentas mínimas, no debemos olvidar la tardía implantación del Estado de bienestar español, en comparación con los de otros países europeos, en un momento en el que éstos ya empezaban a sufrir las transformaciones que la aceptación del paradigma de activación conlleva.

En cualquier caso, lo que nos interesa es desentrañar los elementos de criminalización de la pobreza que pueda contener el modelo de activación vasco, así como identificar sus influencias ideológicas. Por ello, y ya que el informe del SIIS es propuesto como marco conceptual y filosófico al modelo de intervención de Lanbide, a continuación recuperamos las tres ideasfuerza, a nuestro parecer, más importantes de su discurso. Nos referimos al concepto de responsabilidad individual, marcado por la noción de empleabilidad; la idea de la centralidad del empleo como elemento de inclusión; y, por último, la cuestión de la reciprocidad.

Dentro del ámbito de la asistencia social, la idea de disuasión, motivada por la adhesión a las teorías de la elección racional, ha sido frecuentemente concebida como una de las principales potencialidades de la activación. Esta potencialidad se fundamenta en la responsabilidad individual, concepción que, en este contexto, tiende a culpabilizar a las personas desempleadas por no encontrarse trabajando. Así, desde nuestro punto de vista, la finalidad disuasoria, como principio invocado para la defensa de la activación, 
tiene una fuerte vinculación con la criminalización de la pobreza, por su alusión inherente a la responsabilidad individual.

En opinión de Castel, resulta incongruente la asunción de responsabilidades individuales cuando hablamos de situaciones de pobreza y exclusión:

Pues 'montar un proyecto profesional' o, mejor aún, construir un 'itinerario de vida', no es tan sencillo, por ejemplo, cuando se está desempleado o se corre el riesgo de ser desalojado de la casa en que se vive. Se trata incluso de una exigencia que les costaría satisfacer a muchos sujetos bien integrados, que siempre han seguido trayectorias demarcadas (1997: 395).

No resulta evidente constatar la importancia que da el SIIS a la responsabilidad individual, ya que el informe apela constantemente a la responsabilidad colectiva. Sin embargo, el análisis realizado nos ha permitido detectar el mayor peso que da a la primera sobre la segunda, con propuestas como la mejora de la empleabilidad. En este aspecto, la activación, además de tener una finalidad disuasoria, alude a las acciones orientadas al individuo para volverlo más 'empleable', sin poner el foco en la propia demanda de empleo, cuyas duras condiciones podrían ser modificadas mediante políticas de índole macroeconómica.

En este sentido, un Estado que quisiera garantizar el pleno empleo podría diseñar mecanismos de regulación que exigieran la calidad del empleo, de manera que se ajustara a las necesidades de la oferta. Con el mismo objetivo, se podrían crear puestos de trabajo en el ámbito público. No obstante, estas soluciones no entroncan con el espíritu neoliberal, que aboga por la no interferencia de la política en la economía de mercado. En cambio, su influencia lleva a reforzar la idea de que es preciso aumentar la responsabilidad individual en la salida de situaciones de desempleo y pobreza.

En una posición intermedia que permite una mayor intervención del Estado, la solución propuesta por el SIIS en su informe pasa por dotar a los individuos de las capacidades que les permitan competir en el mercado de trabajo. En la misma línea, la llamada tercera vía alienta un escenario donde se provea a los individuos de las habilidades necesarias para gestionar los riesgos inherentes de una forma de Estado moldeada por la cultura empresarial:

La reforma del bienestar debería reconocer los argumentos sobre el riesgo [...]: la gestión eficaz del riesgo (individual o colectivo) no sólo significa minimizar o proteger contra los riesgos; significa también aprovechar el lado positivo o energético del riesgo y suministrar recursos para la adopción del riesgo (Giddens, 1999: 138).

Otra de las ideas-fuerza que hemos considerado más importantes del discurso del SIIS se refiere a la centralidad del empleo como elemento de inclusión social. Debemos comenzar diciendo que este paradigma resulta, de entrada, excluyente. $Y$ es que se está asumiendo que la población inactiva no va a poder estar plenamente integrada en la sociedad, con las graves implicaciones que esto conlleva.

Además, la idea resulta fácilmente refutada con sólo fijarse en las posiciones más acomodadas: encontraríamos gran cantidad de casos de personas ricas sin empleo y, a su vez, perfectamente integradas en la sociedad.

Por otra parte, el hecho de adjudicar al trabajo remunerado la llave de la inclusión social significa querer defender una posición teórica muy alejada de la realidad del mercado laboral actual, caracterizado por unas duras condiciones de precariedad. Y es que una nueva forma de empleo, temporal y parcial, tiende a generalizarse también en Euskadi, sustituyendo al otrora indefinido y a tiempo completo (Zubero, 2010: 272). En este sentido, hay que decir que gran parte de las personas que acceden a las rentas mínimas ya trabajan o han trabajado, siendo muchas de ellas pensionistas. Por el hecho de estar, o haber estado, dentro del mercado laboral, no dejan de ser pobres ni de estar excluidas de la sociedad. En ello coinciden autores como Paugam o Castel, que consideran el deterioro del empleo postfordista la causa principal de la exclusión, por lo que, en este contexto, niegan el potencial rehabilitador del empleo (Pérez Eransus, 2005: 85-86).

Habiendo puesto en entredicho la función integradora del empleo, se desvela la motivación neoliberal del abrazo por parte los 'pobres capaces' a la ética del trabajo. Y es que, tal y como destaca Pérez Eransus, fue la ética protestante europea del siglo XVI la que llevó al trabajo a convertirse en la máxima expresión de la dignidad humana, mientras que una concepción similar fue adoptada por el espíritu liberal en los siglos XVIII y XIX (ibídem: 32-33). El neoliberalismo actual recupera el supuesto valor incuestionable del trabajo, rechazando otros puntos de vista y opciones de vida.

En este sentido, hemos comprobado que el informe del SIIS ofrece un discurso ambiguo en relación a la centralidad del empleo; de la misma manera, el discurso giddensiano también ha mostrado ciertas contradicciones en este punto. Como podemos apreciar en el siguiente extracto de su obra, Anthony Giddens se muestra partidario de reconocer otras opciones de vida al margen de la ética del trabajo:

La participación en la fuerza de trabajo, y no sólo en empleos sin proyección, es claramente vital para atacar la exclusión involuntaria. El trabajo tiene múltiples beneficios: genera ingresos para el individuo, da una sensación de estabilidad y dirección en la vida, y crea riqueza para la sociedad en general. Pero la inclusión ha de extenderse mucho más allá del trabajo, no sólo porque hay mucha gente en cualquier momento incapaz de estar en la fuerza de trabajo, sino porque una 
sociedad dominada en exceso por la ética del trabajo sería un lugar bastante desagradable en el que vivir. Una sociedad inclusiva debe proveer lo suficiente para las necesidades básicas de los que no pueden trabajar, y debe reconocer la mayor diversidad de metas que la vida ofrece (Giddens, 1999: 131).

Sin embargo, líneas más abajo, Giddens alerta de la conocida trampa de la pobreza, habitualmente vinculada a las prestaciones asistenciales, y prima las necesidades del mercado laboral a las de las personas trabajadoras con empleos precarios: "Prestaciones establecidas para contrarrestar el desempleo, por ejemplo, pueden llegar a producir desempleo si se usan activamente como protección frente al mercado de trabajo" (ibídem). En la misma línea, Giddens continúa, más adelante, rechazando esa diversidad de metas que anteriormente defendía:

Los sistemas de prestaciones deberían reformarse cuando induzcan al riesgo moral, y debería estimularse una actitud de adopción de riesgos más activa, allí donde sea posible, mediante incentivos, pero donde sea necesario, mediante obligaciones legales (ibídem: 145).

Vemos que la potencialidad pretendidamente rehabilitadora de la activación esconde elementos de criminalización, al no reconocer la diversidad ideológica y recriminar a las personas pobres, consideradas vagas, el supuesto hecho de no compartir los valores oficiales, que ensalzan el valor del trabajo.

La última idea-fuerza del texto analizado es la referida al concepto de reciprocidad, cuya defensa es la que más espacio ocupa en el argumentario conceptual del documento. De hecho, el informe se atreve a reivindicar una reciprocidad justa. Sin embargo, si realmente estamos hablando de justicia en la reciprocidad, no parece justo exigir a personas que viven en el umbral de la pobreza que se dediquen a realizar actividades laborales, cuando otras personas que viven en la abundancia son totalmente libres de hacer lo que deseen.

Lo que el SIIS reclama en el texto analizado es que toda persona que cobra una prestación social debe realizar una contribución productiva al bien común. Como hemos visto en el análisis del discurso, a pesar de intentar evitar la connotación negativa que conlleva la noción de contrapartida a la prestación, consideramos que en el informe del SIIS se asume como deuda la ayuda prestada y se concibe como medio de pago, exclusivamente, aquel que se enmarca dentro del mercado de trabajo. Este intercambio contractual responde a la necesidad de garantizar el funcionamiento del mercado laboral vigente, ya que, si no fuera el caso, se aceptarían otras formas de contribución a la sociedad, como las actividades voluntarias, el imprescindible trabajo doméstico y de cuidados o el trabajo informal, entre otras. De hecho, es aquí donde, nuevamente, podemos apreciar una lógica de criminalización de las personas desempleadas, al someterlas a la acusación de no contribuir, presuponiendo que el hecho de no participar en el mercado laboral es lo mismo que no contribuir.

Paradójicamente, tomar parte en el mercado laboral no asegura una verdadera contribución al bien común; es más, dados los ingentes niveles de contaminación y esquilme de recursos naturales que implica la actual sociedad de consumo, es posible que a lo que esté contribuyendo sea a la destrucción del planeta. Desde esta perspectiva, ¿dónde se ubicarían los empleos socialmente no deseables?

La coerción ejercida bajo la idea de reciprocidad es acogida con buenos ojos por los posicionamientos neoliberales, con la aparente contradicción que representa toda coacción en el ideario liberal. Sirva de ejemplo el agresivo workfare estadounidense, caracterizado por su fuerte mecanismo sancionador. También los adeptos de la tercera vía son partidarios de reivindicar una lógica de derechos y obligaciones -“ningún derecho sin responsabilidad” (Inza, 2006: 127)-, enmarcadas éstas en el mercado laboral formalizado, que asegure la aclamada competitividad económica -“las estrategias para la creación de empleo y el futuro del trabajo han de estar basados en una orientación hacia las nuevas exigencias económicas" (Giddens, 1999: 146)-.

En síntesis, hemos observado que las principales ideas-fuerza del discurso analizado contienen elementos de criminalización de la pobreza, así como una clara alineación con algunos posicionamientos de los adeptos del Estado social inversor propuesto por Giddens. Concretamente, ambos discursos mantienen posturas coincidentes respecto a la responsabilidad individual y la noción de reciprocidad, e incluso comparten cierta ambigüedad en la defensa de la centralidad del empleo. Hemos apreciado que la influencia neoliberal se hace sentir en todas estas cuestiones, si bien hemos matizado la posición más suave presentada tanto por el documento del SIIS como por la tercera vía, respecto a la primacía de la responsabilidad individual y la centralidad del empleo.

Terminamos, pues, nuestro análisis sobre la política de garantía de ingresos de la CAPV advirtiendo que, detrás del pretendido sentido común del paradigma de activación, se distingue un enfoque de culpabilización de las conductas individuales de las situaciones de pobreza, acorde con los preceptos de la ideología neoliberal.

\section{Conclusiones}

Como es bien sabido, la competencia del mercado internacional y, concretamente, la creación de un mercado único en el caso europeo, provoca que los Estados soberanos tengan menos capacidad de decisión a la hora de diseñar y aplicar políticas de protección social. Los tradicionales Estados de bienestar empiezan a sufrir transformaciones, fruto de la creciente 
subordinación de la política social a las exigencias de la competitividad económica (Inza, 2014: 58).

En el marco de esta supremacía de lo económico sobre lo social, distinguimos dos medidas irrenunciables desde un punto de vista neoliberal. Por una parte, la configuración del mercado capitalista internacional exige la constricción de la protección social con el objeto de reducir los costes relacionados con el empleo, así como la deuda del sector público (Inza, 2012: 118). Matizando esta exigencia, los defensores de la llamada tercera vía abogan, más que por la eliminación del gasto social, por la reducción del denominado gasto pasivo y su reorientación hacia la activación de la población con el objetivo de que cada individuo mantenga la responsabilidad de su bienestar a través de ingresos de mercado (ibídem: 123).

Por otra parte, la otra necesidad intrínseca del sistema económico mundial consiste en la desrregulación de las actividades económicas, al menos en lo que se refiere a las relaciones laborales. Con la omisión de los Estados, los actores del lado de la demanda, las empresas, son libres de configurar las reglas del juego con su capacidad inversora. Para un desarrollo satisfactorio de su actividad, necesitan garantizar que haya disponibilidad de una oferta que se ajuste a esta demanda desrregulada-precarizada.

El paradigma de la activación, o la condicionalidad laboral de la protección social, sirve para la consecución de ambos propósitos: el gasto pasivo, que es visto como un impedimento para la devaluación competitiva de la fuerza de trabajo, es sustituido por mecanismos de incentivo al empleo. Además, estos mecanismos coactivos garantizan la participación de los 'pobres capaces' en el mercado de trabajo, sean cuales sean las exigencias de la demanda desrregulada.

Al igual que el paradigma de la activación sirve a los intereses del neoliberalismo en las dos cuestiones mencionadas, la criminalización de la pobreza representa, a su vez, una eficaz herramienta para llevarlas a cabo. La búsqueda de la reducción del gasto 'pasivo' se ve facilitada por la lógica culpabilizadora, que achaca a la conducta de las personas pobres la responsabilidad de serlo, por lo que la criminalización de la pobreza ayuda aquí a legitimar el sistema de libre mercado. La segunda motivación, de tinte coercitivo, se apoya en las otras ideas o argumentos que también presentan conexiones con la criminalización de la pobreza, en este caso, el potencial 'rehabilitador' de la activación, así como la lógica de la contrapartida a la colectividad.

Así, es principalmente en estas cuestiones de legitimación social del sistema económico y coerción de la clase trabajadora donde el neoliberalismo y el paradigma de la activación entroncan con la criminalización de la pobreza.

Una vez hemos afirmado la triple conexión global entre neoliberalismo, activación y criminalización de la pobreza, se hace necesario apreciar los diferentes modelos de activación existentes, con objeto de acercarnos al caso concreto de la CAPV. Mientras que en la mayoría de los países europeos aún domina una concepción más estructuralista de la pobreza y, por tanto, la respuesta al riesgo de desempleo es vista como una responsabilidad compartida por toda la sociedad, en EE.UU. triunfa una ideología individualista que concibe el desempleo como resultado de las decisiones voluntarias de los individuos. Debido a esta diferencia en el pensamiento, mientras que la introducción de los mecanismos de activación en los programas asistenciales europeos ha solido tener como principal objetivo la inclusión social de las personas usuarias (activación-welfare), en EE.UU. los programas de activación-workfare han tenido siempre un carácter más bien disuasorio (Pérez Eransus, 2005: 69). Motivado por el control social de las personas usuarias, este modelo presenta niveles más bajos de prestaciones, se identifica con un fuerte contenido de obligatoriedad y suele utilizar mecanismos sancionadores (ibídem: 143). Por el contrario, el modelo welfare busca favorecer la participación social de los individuos y supone, en definitiva, un recurso más matizado a los elementos de criminalización de la pobreza.

Respecto al caso concreto de la CAPV, el análisis realizado nos ha ayudado a desentrañar una lógica de criminalización de la pobreza en las tres ideas-fuerza del discurso que inspira la política vasca de garantía de ingresos: la responsabilidad individual, la centralidad del empleo y la reciprocidad. Por otra parte, el mismo análisis también nos ha ayudado a vislumbrar la analogía entre el marco conceptual del paradigma de activación en la política social vasca y los posicionamientos de la llamada tercera vía, propuesta por Anthony Giddens. Esta última tiene planteamientos similares a los del neoliberalismo respecto a la supremacía de lo económico sobre todo lo demás, incluido lo social, y también prima la responsabilidad individual sobre la colectiva, aunque de manera más sosegada. La característica principal que los diferencia es que desde la tercera vía no se percibe el gasto social como un impedimento para el crecimiento. De hecho, las políticas sociales son incluidas como un factor productivo, siempre y cuando su orientación sea netamente activadora. El Estado social inversor, precisamente, invierte en capital humano y hace un uso eficiente de él, a través de políticas activas de empleo y otros mecanismos, "mientras se fomenta una mayor inclusión social, facilitando el acceso al mercado de trabajo" (Inza, 2012: 123). Así, la orientación giddensiana que se desprende del discurso analizado encuadra las políticas sociales de activación en un enfoque de activaciónwelfare, todavía alejado del workfare neoliberal más restrictivo. Asumiendo, pues, un modelo de activación de tipo welfare, e independientemente de la severidad en los posicionamientos culpabilizadores, creemos que la estrategia activadora atiende a los reclamos/necesidades del neoliberalismo, con los que comenzábamos este apartado de conclusiones.

A pesar de que no podemos afirmar relaciones de causalidad inequívocas en relaciones económi- 
cas, sociales y políticas tan complejas, ni concebir las políticas de activación como una herramienta diseñada ad hoc para mantener el actual sistema neoliberal, la verdad es que, de acuerdo a las reglas competitivas de éste, los Estados desean hacer a sus trabajadores más atractivos a los inversores, por lo que terminan cediendo ante las empresas multinacionales y los poderes financieros, que consiguen así presionar a la baja todo sistema de protección social (Inza, 2006: 121). Esto incluye la introducción de mecanismos de activación o condicionalidad.

Desde el momento en el que se consiente hablar en términos de condicionalidad sobre los programas de garantía de ingresos, se abre la puerta a un mayor o menor grado de criminalización de la pobreza, la cual sirve de legitimador social al sistema políticoeconómico actual, que no puede permitirse proveer de bienestar a los que quedan al margen del mercado laboral. De hecho, con la emergencia del precariado como nuevo grupo social, la pobreza se extiende, cada vez más, a otras situaciones que van más allá del desempleo o la vejez (Zalakain, 2014: 18). Por otra parte, la criminalización de la pobreza también se hace sentir en el reforzamiento de los sistemas de control y sanción que, según Sanzo, suelen acompañar a esta orientación activadora (2013: 21).

Loïc Wacquant lleva décadas combinando los estudios de política penal y política social para mostrar la dualidad de las políticas para las personas pobres en el ámbito estadounidense. Según el análisis de este autor, la criminalización de la pobreza se convierte en un factor clave de estas políticas, en tanto en cuanto los medios para 'gestionar' la miseria suelen ser la cárcel, así como la reorganización de los servicios sociales como instrumentos de vigilancia (González Sánchez, 2011). La práctica gubernamental neoliberal dedicada al desmantelamiento de los servicios sociales conlleva el aumento de las prerrogativas del Estado en su faceta más coercitiva, con objeto de gestionar la pobreza. La 'mano invisible del mercado' parece no ser suficiente para mantener el orden social; se hace entonces necesario 'el puño de hierro del Estado' (Wacquant, 2000: 166). En las últimas décadas, y continuando con otra metáfora, esta vez bourdieuana, la tradicional 'mano izquierda' del Estado, que ha solido regular las clases trabajadoras mediante legislación laboral, educación, sanidad, asistencia social y viviendas sociales, está siendo sustituida -en EE.UU.o complementada -en la Unión Europea- con su 'mano derecha', es decir, policía, justicia y acciones correctivas (Wacquant, 2011: 145).

Lejos, todavía, de la concepción más severa de criminalización de la pobreza que aporta el análisis wacquantiano, la tendencia a subordinar la protección social a los condicionamientos laborales supone el comienzo de una transición desde una sociedad solidaria e inclusiva a otra de signo autoritario, una evolución cuya culminación podría resultar fatal.

Por todo ello, consideramos necesario un cambio en el tratamiento de las personas que viven en situación de pobreza que permita la aplicación de protocolos amplios de inclusión social que acaben con la condicionalidad y funcionen desde un prisma fundamental de solidaridad. Dada la diversidad de opciones de vida, el proceso de integración debe ser construido con los y las interesadas, sin el amarre a ningún contenido obligacional (Pacheco-Mangas y HernándezEchegaray, 2013: 112). El reto es asumir un concepto de ciudadanía que incluya la universalidad de los derechos civiles, políticos, sociales y económicos, y se distancie de la peligrosa senda demarcada por la condicionalidad de aquéllos. 
(1998): “Ley 12/1998, de 22 de mayo, contra la exclusión social”, Boletín Oficial del País Vasco, no 105 , 8-6-1998, págs. 10.467-10.506 [<http://www. lehendakaritza.ejgv.euskadi.net/r48-bopv2/ es/bopv2/datos/2007/07/0703900a.pdf)].

CASTEL, R. (1997): Las metamorfosis de la cuestión social: una crónica del salariado, Buenos Aires, Paidós.

GIDDENS, A. (1999): La tercera vía: la renovación de la socialdemocracia, Madrid, Taurus.

GONZÁLEZ SÁNCHEZ, I. (2011): "Redefiniendo la pobreza y la penalidad: la formación del Estado neoliberal”, Revista Española de Sociología, n- 15, págs. 97-102.

INZA, A. (2014): “La mercantilización del bienestar y el reforzamiento del Estado disciplinario", Revista de Investigaciones Políticas y Sociológicas, $\mathrm{n}-13$.

- (2012): “Paradigmas de Estado y precarización del mercado de trabajo: hacia un sistema darwinista”, Inguruak, noํ 51, págs. 117-129.

- (2006): “Consecuencias de la sobrecarga del Estado y la globalización en la concepción del Estado de bienestar. Hacia un régimen de prestaciones sociales condicionadas", Papers. Revista de Sociología, no 81, págs. 119-129 [rhttp:// www.raco.cat/index.php/Papers/article/ viewArticle/55648/o>].

KERBO, H. R. (2004): Estratificación social y desigualdad. El conflicto de clase en perspectiva histórica, global y comparada, McGraw-Hill.
PACHECO-MANGAS, J.; y HERNÁNDEZ-ECHEGARAY, A. (2013): "Los sistemas de rentas mínimas: protección social, ciudadanía y clientelismo político. Un análisis comparado entre Andalucía y Castilla y León”, Zerbitzuan, no56, págs. 101-114 [<http:// dx.doi.org/10.5569/1134-7147.56.07>].

PÉREZ ERANSUS, B. (2005): Políticas de activación y rentas mínimas, Madrid, Cáritas.

SANZO, L. (2013): "La política de garantía de ingresos en Euskadi”, Zerbitzuan, nํㅗ 53, págs. 9-28 [khttp://dx.doi.org/10.5569/1134-7147.53.01)].

SIIS CENTRO DE DOCUMENTACIÓN Y ESTUDIOS (2011): Activación y derecho a la inclusión en el marco de las políticas de empleo y de garantía de ingresos en la CAPV. Documento de trabajo [<http://www.siis.net/documentos/ ficha/197806.pdf $\rangle$.

WACQUANT, L. (2011): “Poner orden a la inseguridad. Polarización social y recrudecimiento punitivo", Revista Catalana de Seguretat Pública, no 24, págs. 141-155.

- (2000): Las cárceles de la miseria, Buenos Aires, Manantial.

ZALAKAIN, J. (2014): "Políticas de apoyo a las familias en Europa: nuevos contextos y nuevas orientaciones", Zerbitzuan, no 56 , págs. 17-39 [khttp://dx.doi.org/10.5569/1134-7147.56.02)].
2010): "Políticas de empleo y cohesión social", Ekonomiaz, noํㅡㄹ. págs. 250-285 [khttp://ideas. repec.org/a/ekz/ekonoz/2010309.html ]. 